\title{
VALORES ÉTICOS EN DECISIONES DE PEQUEÑOS AGRICULTORES CONFRONTADOS CON PERCEPCIONES DE ESTUDIANTES DE AGRONOMÍA (UNIVERSIDAD DE CALDAS)
}

\author{
SERGIO ALEJANDRO ÚSUGA SÁNCHEZ ${ }^{1}$, MARÍA ELENA BERNAL VERA² Y ÉLMER CASTAÑO \\ RAMÍREZ \\ elmercr@ucaldas.edu.co
}

Manizales, 2010-12-02 (Rev. 2011-03-26)

\section{RESUMEN}

En este trabajo se determinan valores que guían a los agricultores frente a decisiones de producción, vida colectiva y ambiente en confrontación con las percepciones de los estudiantes de Agronomía y agrónomos egresados de la Universidad de Caldas. Mediante una metodología descriptiva, se trabajó con tres comunidades de pequeños agricultores para designar sus valores mediante una entrevista semiestructurada, y con sus resultados se cursó una encuesta a estudiantes y agrónomos, se identificaron puntos de encuentro y desencuentro y se sugirieron propuestas formativas en ética agronómica. Los pequeños agricultores reconocen como sus valores de expresión colectiva: responsabilidad, familia, tradición, trabajo, honorabilidad, cooperación, solidaridad, la educación como valor deseado y como valores de expresión individual: orgullo, pertenencia, bienestar, autosuficiencia. Todos los estudiantes de la Facultad coinciden en reconocer algunos de los valores sociales centrales enunciados por los productores agrarios como son: responsabilidad, solidaridad, trabajo, cooperación; en la medida en que avanzan en su formación profesional añaden otros valores y cuando egresan se centran solo en los dos primeros. Hipotéticamente, los estudiantes del programa de Agronomía se ubican de manera ideal en niveles postconvencionales en la escala de valores de Kohlberg, no obstante cuando egresan parecen retroceder en sus concepciones en la medida en que en niveles superiores y entre los egresados

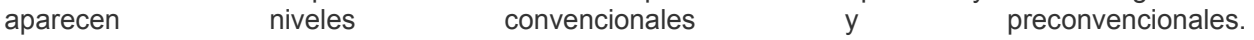

PALABRAS CLAVE:

Valores pequeños agricultores, confrontación valoral agrónomos vs. agricultores, percepción valoral estudiantes de Agronomía.

\section{ETHICAL VALUES IN DECISIONS OF SMALL FARMERS CONFRONTED WITH AGRONOMY STUDENTS' PERCEPTIONS (UNIVERSIDAD DE CALDAS, COLOMBIA)}

\section{ABSTRACT}

In this work, values that guide small farmers when facing production decisions, collective life and environment, in confrontation with the perceptions of the Agronomy alumni from Universidad de Caldas are determined. Using a descriptive methodology, three small farmer communities were worked with to designate their values using a semi-structured interview which results were used to apply a survey to students and agronomists. Agreement and disagreement points were identified and formative proposals in agronomic ethics rose. Small farmers identify their collective expression values: responsibility, family, tradition, work, honesty, cooperation, solidarity, education as a desired value; and as individual expression values: pride, membership, welfare, self-sufficiency. All the students from the Faculty coincide in recognizing some of the central social values stated by the agricultural producers such as: responsibility, solidarity, work, cooperation; as they progress in their professional education, they add other values but when they graduate they focus on the two first ones. Hypothetically, the Agronomy Program students are placed in post-conventional levels in Kohlberg's value scale. However, when they graduate it seems to be they back down in their conceptions while in superior levels and among the alumni conventional and pre-conventional levels appear.

KEY WORDS: small farmers values, farmer vs. agronomists values confrontation, perception of values in Agronomy students.

\section{INTRODUCCIÓN}

El análisis de los hechos socioculturales en lo rural, se ha determinado desde todo el fundamento teórico de las ciencias sociales, siendo necesario pero no suficiente para alcanzar una total 
comprensión de estos fenómenos; este análisis debe ser completado desde lo ético. La perspectiva teórica que considera, dogmática y apriorísticamente, que todos los comportamientos valorativos, simbólicos-axiológicos son meros reflejos y expresiones subordinadas de la estructura económica, no resulta a veces una perspectiva competente para la explicación de ciertos procesos en situaciones específicas, como son algunas posturas ambientales, sociales y otras dramáticamente humanas como la defensa de la vida y la dignidad.

En el ejercicio de su profesión, el agrónomo al interactuar con los agricultores busca transmitirles un manejo de sus cultivos, acorde con los conocimientos teóricos que ha adquirido en la academia y en el ejercicio de su profesión y, en muchos casos, la técnica que difunde contrasta con el conocimiento empírico de los agricultores. La forma de actuar de agrónomos y campesinos frente a una situación agrícola o ambiental, está determinada por el desarrollo cognitivo para los primeros y por el desarrollo cognitivo y valorativo para los segundos, lo que se da por procesos de aprendizaje diferentes, en contextos igualmente distintos, donde la academia contribuye a construir la manera como el estudiante y, posteriormente el agrónomo, valora al productor.

La pregunta aquí es: ¿Hasta dónde difieren las percepciones valorales de los estudiantes de Agronomía de los sistemas de valores de los agricultores? Este es el interrogante que guió este trabajo, que cumple con el propósito de determinar los valores que guían a los agricultores frente a decisiones de producción, vida colectiva y ambiente en confrontación con las percepciones que tienen de ellos los estudiantes de Agronomía (en sus distintos niveles de formación) y agrónomos egresados de la Universidad de Caldas, detectando puntos comunes y diferencias.

\section{REVISIÓN DE LITERATURA}

La palabra moral deriva del latín moralis que significa costumbre, todo lo que viene de fuera, lo que está impuesto por normas, leyes, códigos (Torres citado por Salazar, Serna \& López, 2007). Es, entonces, el conjunto de comportamientos y normas que se suelen aceptar como válidos (Savater citado por Salazar et al., 2007). Aunque la palabra ética proviene del griego ethos, que también significa costumbre, se define actualmente como la reflexión que se hace de las normas y los comportamientos propios y la comparación con morales diferentes (Salazar et al., 2007); esta reflexión se logra a través de la interrogación y el diálogo, a sabiendas de que el hombre como ser social necesita convivir con los demás (Hartman citado por Salazar et al., 2007).

Sobre el concepto de ética Savater (citado por Salazar et al., 2007) afirma que:

la ética no es más que el intento racional de cómo vivir mejor; se ocupa de lo que un individuo hace con su libertad, en la ética lo importante es querer bien. La ética es una actitud, una reflexión individual sobre la libertad propia en relación con la libertad de los demás, la ética tiene alcances humanísticos más radicales y profundos que las soluciones o propuestas desarrolladas desde la esfera política. Ética es una reflexión sobre las circunstancias en que vive el hombre en un mundo real y no un código que nos explica cómo movernos.(p. 24).

Para Maturana (citado por Vila, 2004):

la ética surge de nuestra preocupación por las consecuencias de las acciones sobre los demás dentro de un marco intercultural, donde las propias culturas deben ser vistas como redes de conversaciones por lo que el ser cultural implica el vivir en tal red. Esas redes por su naturaleza social están impregnadas de valores que deberán ser configurados intersubjetivamente y aceptados de manera universal por los actores sociales para ser legítimos en función de su interés común, sin ningún tipo de exclusiones. (p. 50)

Este trabajo de investigación se va a apoyar principalmente en la ética dialógica, expuesta principalmente por filósofos morales como Apel y Habermas. De acuerdo con Salazar et al. (2007) basándose en el texto de Adela Cortina -Ética mínima, (2000)-: "la ética dialógica fundamenta la democracia integral, hunde sus raíces en la tradición del diálogo socrático, es una ética normativa que intenta fundamentar el hecho de que haya moral y de que deba haberla". (p. 33). Sostienen que la liberación humana tendrá lugar si, además de la técnica, crece la disponibilidad de los hombres a tomar decisiones a través de consensos en los que estén atendidos los intereses universales.

Villarroel (2004) hablando sobre la relación entre el análisis weberiano y la ética del discurso o dialógica, expresa que en ambas corrientes de pensamiento: 
la modernidad se analiza entendiendo que las consecuencias del creciente proceso de racionalización y de descentramiento-diferenciación de las imágenes mítico-religiosas del mundo, constituyen la expresión de un tránsito vertiginoso que sacó a la humanidad de una estructuración anterior, marcada por referentes de carácter fraternal y comunitario, en la que los lazos de pertenencia estaban determinados por las tradiciones vinculantes, para llevarla a la configuración de estructuras societarias definidamente individualistas. (p. 3).

Para Villarroel la ética discursiva no pretende orientar sobre el que hacer, sino que proporciona un procedimiento lleno de presupuestos que debe garantizar siempre la imparcialidad en la formación del juicio.

La ética dialógica parte de la tesis de que la evolución cognitiva desemboca en una concepción descentrada del mundo (Habermas, 1994 citado por Quintero, 2004), en la que el modelo de acción comunicativa propuesta por Habermas identifica al lenguaje como el medio y el centro de la comunicación orientada a la producción de un acuerdo entre los interlocutores en torno a algún fenómeno del mundo objetivo, social o subjetivo que le permita coordinar sus acciones respectivas (Sieglin, 2004) lo que facilitaría una conciliación entre academia y agricultor.

Según Lara (1990), lo que se busca con esta comunicación es encontrar lo igual y lo distinto en el otro. Afirma que "la dialéctica de identidad entre diferentes, hace parte del reconocimiento de la coexistencia entre los hombres, la eticidad". (p. 258). En el análisis que realiza de Habermas, habla de la autorreflexión crítica como conocimiento que puede construir una voluntad política capaz de indagar sobre el sentido de los deseos, de los valores, de la acción y de su articulación e institucionalización como formas de vida. Lo anterior, permite conseguir la máxima ilustración en la cual la toma de decisiones se hace a partir de una discusión pública que no tiene coerciones de ningún tipo, que reconoce la necesidad de participación de todo el colectivo social. Y si se desea tomar el camino de la racionalidad es a partir de un diálogo, en que se incluyan todas las cuestiones que pertenecen a las distintas esferas del saber que son compartidas en la intersubjetividad (verdad, rectitud y sinceridad).

Siurana (2000), converge en este escenario con Lara, pues igualmente se basa en Habermas que:

defiende que los sujetos, en los contextos de experiencia y acción del mundo de la vida, realizan actos de habla para los que reclaman las cuatro siguientes pretensiones performa-tivas de validez: 1) la pretensión de inteligibilidad, según la cual el hablante pretende que el oyente le entienda, adaptando, por ejemplo, el idioma o el número de tecnicismos al idioma o nivel de formación del oyente. 2) La pretensión de verdad, referida a algo en el mundo objetivo, como la totalidad de las realidades existentes. 3) La pretensión de corrección normativa, referida a algo en el mundo social, como la totalidad de relaciones interpersonales legítimamente reguladas. 4) La pretensión de veracidad, referida a algo en el propio mundo subjetivo, como la totalidad de las vivencias a las cuales el sujeto tiene acceso privilegiado. (Siurana, 2000 p 56)

Lazega (2004) en un análisis sobre Coleman, utiliza el término disciplina social para referirse a la capacidad del actor de auto-reprimirse durante sus negociaciones con otros, en la definición de sus propios intereses individuales y de la amplitud del campo de sus reivindicaciones, así como en el ejercicio de su poder individual, en particular de su poder de explotación. Esta es sinónimo de una capacidad de politización que incita al actor a introducir la duración en sus intercambios. Permite repensar la relación entre la racionalidad individual y la estructura social. Desde el punto de vista del individuo, la auto-restricción en las negociaciones deriva de la politización de los intercambios, de la aplicación de compromisos constitutivos de relaciones sociales. Desde el punto de vista de la colectividad, se trata de procesos sociales que se apoyan en esta aplicación: por ejemplo, los procesos de solidaridad, de control y de regulación. Se puede ilustrar esta articulación entre intereses relacionales y procesos sociales, por medio de tres procesos específicos que aseguran su estabilidad. Lazega (2004) determina los diferentes procesos así:

- El primer proceso social de resolución de problemas de la acción colectiva entre actores, se soporta sobre la creación de un sistema de intercambio generalizado y múltiple. Este sistema ayuda a los miembros a negociar diversos tipos de recursos ligados a la producción, directamente o indirectamente, permitiendo una circulación duradera a la vez que suspendiendo parcialmente el comportamiento percibido como oportunista.

- Un segundo proceso genérico, consiste en una organización informal de las llamadas al orden entre los miembros. Frente a comportamientos desviados o percibidos como oportunistas, un grupo social hace funcionar un sistema de control social que le ayuda a seleccionar sanciones y a construir un acceso personalizado a los desviados a quienes hay que recordar sus compromisos. 
- $\quad Y$ un tercer proceso en que la aproximación estructural y el diálogo permiten formalizar el proceso de regulación, es decir, la redefinición de las reglas del juego entre los miembros, de las normas que estabilizan sus compromisos y sus intercambios sociales.

La otra visión, la que ha sido marginada, es la del pequeño agricultor, el cual durante la gestión de su agroecosistema aplica su capacidad cognitiva con un importante acervo de experiencias útiles, que representan un gran papel en la racionalidad ecológica productiva. "Rechaza el mito de la superioridad del mundo urbano industrial sobre el mundo rural, como argumento usado para justificar la destrucción de la cultura campesina tradicional, como una condición básica para la modernización de la producción local" (Martínez, 2008, p. 10). Durston (2002) sugiere a los investigadores que: "los programas de superación de la pobreza campesina y de fortalecimiento de la sociedad civil rural tendrían mejores resultados si tomaran en consideración los sistemas socioculturales de las comunidades" (p. 12).

Ya Bebbington en 1990 citaba diversos autores (Brush, Field, Chiriboga, Gade, Rhoades y SánchezParga) que reconocían la profundidad y detalle del conocimiento agronómico de los campesinos, así como su capacidad de crear, experimentar y responder al cambio. Altieri (citado por Martínez, 2008) plantea cuatro dimensiones del conocimiento tradicional campesino, que tienen una profunda sabiduría alrededor del suelo, clima, vegetación, animales y ecosistema, las que traducidas en estrategias múltiples de producción basadas en agroecosistemas diversificados con diferentes especies, generan aunque con limitaciones técnicas y ecológicas, la autosuficiencia alimentaria. Entre ellas se pueden mencionar:

Conocimiento sobre taxonomías biológicas locales: utilizan sistemas para clasificar plantas y animales, donde el nombre tradicional de una planta o animal revela el estatus taxonómico de ese organismo. "Existen diversas evidencias que reflejan una alta correlación entre la taxa campesina y la científica" (Altieri citado por Martínez, 2008, p. 7).

Conocimiento sobre el entorno natural: poseen conocimientos sobre aspectos geográficos (clima, nubes, vientos, montañas, altitud); físicos (topografía, minerales, suelos, microclima, agua, etc.); vegetacionales (conjunto de masas de vegetación), y biológicos (plantas, animales y hongos). Estos conocimientos les permiten resolver problemas concretos y prácticos durante la gestión de su agroecosistema.

Conocimiento sobre las prácticas agroproductivas: procuran mantener la diversidad, continuidad temporal y espacial; utilizar óptimamente los recursos y el espacio; reciclar nutrientes; conservar y manejar el agua; controlar la sucesión y protección del cultivo.

Conocimiento campesino experimental: el campesino tiene la capacidad de observar el agroecosistema que interviene y adquirir conocimientos empíricos. Esto se demuestra históricamente en la selección de variedades de semilla para ambientes específicos, de naturaleza casi simbiótica.

Sack (citado por Bebbington, 1990) refuerza la importancia del conocimiento empírico al afirmar que:

el trabajo es la práctica productiva; en el caso del campesino la relación directa e íntima con el medio ambiente. Es aquí donde la tecnología adquiere gran importancia, media entre el ser humano y la naturaleza, bien a corto plazo o a largo plazo. Es en el proceso de trabajo donde el campesino aprende, experimenta y crea la práctica técnica, los conocimientos edáficos y climáticos, etcétera. Es aquí, experimentando la variabilidad de la naturaleza, donde el campesino se vuelve desconfiado ante los esfuerzos de los científicos y técnicos porque éstos generalizan. (p. 13)

Habermas, siguiendo con la tradición de la Escuela de Frankfurt, construye una teoría crítica de la sociedad capitalista postindustrial. "En ella la conciencia tecnocrática desarrollada a través de la ideología científica diluye la relación capital-trabajo reinterpretando a través de una ilusión racionalizadora la explotación y opresión" (Sevilla, et al., 2001, p. 3). En palabras de Habermas (citado por Sevilla et al., 2001): "la conciencia tecnocrática refleja no solo la separación de una situación ética sino que mantiene al hombre aparte de la represión que la ética, como una categoría de la vida puede ejercer sobre él"(Ibíd).

La racionalidad de las opiniones y de las acciones es un tema que tradicionalmente se ha venido tratando en filosofía. Puede incluso decirse que el pensamiento filosófico nace de la reflexivización de la razón encarnada en el conocimiento, en el habla y en las acciones. El tema fundamental de la filosofía es la razón. (Habermas, 1999, p. 15) 
Según Leff (citado por Ceretti y García, 2006) las racionalidades son sistemas de reglas de pensamiento y comportamiento de actores sociales que se establecen dentro de estructuras económicas, políticas e ideológicas, legitimando un conjunto de acciones, confiriendo un sentido a la organización de la sociedad en su conjunto"(p. 2).

Weber (citado por Aguilera, 2004), construye tres tipos de racionalidad:

a) Racionalidad teórico formal: permite el control consciente de la realidad a través de la creación de conceptos cada vez más precisos y abstractos, que puedan explicar las cosmovisiones del mundo regido por los modos de producción y de vida.

b) Racionalidad instrumental: consecución metódica de determinado fin práctico por medio de un cálculo preciso de recursos eficaces.

c) Racionalidad sustantiva: ordena la acción social en patrones basados en postulados de valor; estos varían en comprensibilidad, contenido y consistencia interna, y son irreductibles a un esquema de relaciones entre fines y medios eficaces. La racionalidad sustantiva plantea el pluralismo cultural, la relatividad axiológica y el conflicto social causado por la diversidad de valores e intereses. (p. 6).

Aquí es menester introducir los elementos del llamado desarrollo moral propuesto por Kohlberg, y que en este trabajo se aplican a los estudiantes de Agronomía de la Universidad de Caldas. Kohlberg define que el desarrollo moral de un individuo pasa por tres niveles y que cada nivel se compone de dos etapas (Portillo 2005, Dote 2006):

1) El primer nivel es el preconvencional en el cual las normas son una realidad externa, que se respetan por las consecuencias que se derivan del incumplimiento o por el poder del que las establece. Los dos estadios son Heteronomía e Individualismo. En la Heteronomía se actúa por obediencia y miedo al castigo. En el Individualismo se cumplen las normas si satisfacen los propios intereses, pero reconocen como justo que los otros también busquen la satisfacción de sus intereses.

2) El segundo nivel es el convencional en el cual las personas se identifican con el grupo, y quieren actuar de forma que se responda a las expectativas que tienen de ellos las personas. Los dos estadios son Mutualidad y Ley y Orden. En la Mutualidad el miedo al castigo se reemplaza por el deseo de cumplir con las expectativas de las personas próximas. En Ley y Orden el deseo es cumplir con las normas sociales establecidas para el bien común.

3) El tercer nivel es el postconvencional en el cual se van adquiriendo, a través de la razón, los principios universales. Los dos estadios son la Utilidad y la Autonomía. En la Utilidad se reconoce que todos los seres humanos tienen derecho a la vida y la libertad por encima de las instituciones sociales. En la Autonomía se llega a la concepción de la prioridad de los principios éticos universales como son los principios de la justicia, en la que se busca la igualdad de derechos de los seres humanos y el respeto a su dignidad de individuos.

Tal autonomía no se entiende como ejercida por individuos aislados, sino como realizable a través de diálogos intersubjetivos. Como medio propio para expresar la autonomía humana, el diálogo permite a la ética situarse a medio camino entre el absolutismo, que defiende unilateralmente un código moral determinado, y el relativismo, que disuelve la moralidad; entre el utopismo, que asegura la llegada inminente de un mundo perfecto, y el pragmatismo, que elimina toda dimensión utópica perdiéndose en la pura estrategia presente o, lo que es idéntico, en la inmoralidad. (Cortina, 2000 , p. 25)

"La educación crítica solo es posible por referencia a un criterio que permita juzgar los conocimientos y valores que se transmiten en la actualidad, e indique hacia dónde se debe tender para progresar éticamente" (Apel citado por Siurana, 2000, p.26). En cuanto a la educación para promover un desarrollo moral de los estudiantes, Vasco (1989) afirma que:

con respecto a la formación ética se trata de superar la enseñanza de acciones particulares como buenas o malas y referirse a la formación de la capacidad para juzgar las acciones a la luz de los principios morales que a su vez hacen referencia al criterio de la dignidad de la persona. (p. 151).

Este concepto de dignidad se desprende de Kant, para quien la dignidad humana es incomparable y no tiene valor equivalente, por lo cual no es un valor relativo ni un precio, sino el valor intrínseco de la existencia (Alarcón y Bernal, 2003). Porque de acuerdo a lo expresado por Escámez y Gil (citados por Vila, 2004): "La dignidad de cualquier persona clama por el reconocimiento de sus derechos y la 
satisfacción de sus necesidades hasta donde alcance el poder de hacerlo" (p. 52). Esto, continúa Escámez y Gil, conlleva a la ética de la responsabilidad en la cual "se pone el acento en los otros especialmente en los más débiles y excluidos y en la naturaleza que hace posible la vida humana" (Ibíd). Éste es un compromiso ético que exige una serie de transformaciones, ya que los escenarios sociales actuales en los que se producen las relaciones reales de las personas y las condiciones políticas y económicas, provocan la injusta marginación de muchas personas y comunidades enteras (Escámez y Gil, citados por Vila, 2004).

Sieglin (2004), hace su aporte para tener claridad sobre cómo las personas actúan en el nivel convencional para cumplir con las expectativas del grupo social. Según Sieglin:

Los individuos como miembros de un grupo social comparten con los demás integrantes de su conjunto una serie de convicciones y saberes que les indican lo que es el mundo y cómo interactuar con los demás en este universo social. Los valores y normas aportan modelos de cómo resolver o evitar determinados problemas y distribuyen por medio de los roles sociales, diferentes tareas y espacios a los actores. Además, guían a los actores en la interpretación de situaciones y acontecimientos, y los orientan en la evaluación de una forma de interacción como pertinente o impertinente. Los individuos interactúan en función de una normatividad intersubjetivamente reconocida por ejemplo, por solidaridad, amor, amistad, odio o protesta y por cumplir cierto tipo de expectativas sociales al ser titulares de determinados papeles sociales. (p. 69)

Para alcanzar un desarrollo moral en la academia, se debe procurar que en el estadio cuarto del nivel convencional se resuelva la crisis de la moral relativista. Esto se logra con el descubrimiento de que a pesar de los límites e injusticia de un sistema social, existe un fundamento racional humano, una "ley natural" fundamento de toda ley humana. De esta manera, las reglas sociales ya no se conciben como producto de un sistema social, sino como resultado de un "contrato social" en el cual las personas reconocen la legitimidad racional de las reglas que ellas mismas se dan, con esto se alcanza el estadio cinco del nivel postconvencional. Lo siguiente aquí, es que la persona en su evolución de la concepción ética descubra en el reconocimiento de la dignidad humana el fundamento para la calidad de los juicios y los compromisos morales (Guindon, 1990).

"Los valores elementales asociados a los seres humanos podrán fundamentarse como una condición indispensable para el respeto mutuo entre posibles interlocutores, que de este modo podrán verse como semejantes aunque no pertenezcan de hecho a las mismas sociedades históricas" (Alútiza, 2005, p. 47).

A continuación, se muestran definiciones de algunos valores expuestos por los agricultores entrevistados en este trabajo:

o Confianza: en el sentido que le da Durston (2002), la confianza individual es una actitud que se basa en el comportamiento que se espera de la otra persona que participa en la relación que se establece entre ambas.

o Autonomía: es la capacidad que tiene la persona de formularse sus propias leyes luego de una reflexión crítica, independiente de determinaciones ajenas o del influjo de emociones y pasiones (Papacchini, 2000).

o Autosuficiencia: Es un valor típico de la unidad de producción familiar indígena y campesina, que consume gran parte de su propia producción. Hay un predominio de los valores de uso sobre los valores de cambio (Martínez, 2008).

o Bienestar: para Valdés (1991), es una combinación de circunstancias exteriores ajustadas a la posesión de ciertos bienes materiales y circunstancias interiores correspondientes a estados de ánimo considerados valiosos.

o Responsabilidad: para Jonas (1995 citado por Leyton, 2005), es obrar de tal modo que los efectos de la acción sean compatibles con la permanencia de una vida humana auténtica en la Tierra.

o Tradición: "Abarca las costumbres, tanto familiares como las comunitarias. Incluye el legado de los ancestros y también la religiosidad popular" (Maza, n.f.p.1).

o Trabajo: conjunto de valores y creencias relacionados con el quehacer que las personas desarrollan antes de alcanzar la mayoría de edad laboral, y durante el proceso de incorporación al mundo de la labranza en el caso de los agricultores (Alcover et al. citados por Blanch, 2007).

o Familia: "Célula básica de la sociedad, que cumple con la función de ser el ente principal para la transmisión de valores a través del proceso de endoculturación de sus nuevos miembros" (Rodríguez, Herrera, Quiles \& Álvarez, 2008, p. 217).

o Cooperación: se trata de una acción complementaria orientada al logro de los objetivos compartidos de un emprendimiento común. No debe confundirse con la colaboración, que es el intercambio de aportes entre aliados que tienen emprendimientos y objetivos diferentes aunque compatibles (Durston, 2002). 
O Educación: para Gadamer (citado por Esquivel, 2009), es un proceso natural que cada cual acepta siempre cordialmente procurando entenderse con los demás.

o Orgullo: para Hume (citado por Pérez, 2002), el orgullo definido positivamente es tener conciencia de las virtudes y considerarlas importantes.

o Pertenencia: "El valor de la pertenencia se expresa en aquellos comportamientos sustentados en el amor por una organización social, lo que lleva a la participación de un espacio común, real o imaginario, que permite sentirse dentro y compartir significados, metas, aspiraciones, valores e ideales" (Universidad Nacional de Colombia, 2010, p.4)

Complementariamente, Boni, Lozano y Monterde (2003) hablan de cinco valores fundamentales que se han logrado justificar racionalmente: libertad, igualdad, solidaridad, respeto activo y diálogo; todos estos están contenidos en el valor de la justicia y dan las siguientes definiciones:

- Libertad: es el primer valor a tener en cuenta porque es el presupuesto para la existencia de todos los demás. Cuando la ética dice lo que se debe hacer en conciencia, la libertad para escoger entre varias posibilidades tiene que estar presupuesta. La libertad es pues la condición de posibilidad del sentido de cualquier enunciado que se refiera a lo que se debe hacer.

- Igualdad: tiene distintas acepciones: las mismas posibilidades de todos los ciudadanos ante la ley, similaridad de oportunidades y justicia equitativa en ciertas prestaciones sociales. Todas estas nociones son políticas y económicas y hunden sus raíces en una idea más profunda: todas las personas son iguales en dignidad, hecho por el cual todas merecen igual consideración y respeto.

- Solidaridad: tiene que ver con el esfuerzo por llevar la libertad, la igualdad y el resto de valores morales, es decir, la justicia, a aquellos que no pueden disfrutar de esos valores. Mientras que la caridad es una acción puntual para dar a otros algo que sobra, mediante la solidaridad se reflexiona sobre las injusticias políticas, económicas o de otro tipo y se realizan acciones dirigidas a erradicarlas.

- Respeto activo: es el interés por comprender a otros y por ayudar a llevar adelante sus planes de vida. En un mundo de desiguales, sin un respeto activo es imposible que todos puedan desarrollar sus proyectos de vida, porque los más débiles rara vez estarán en condiciones de hacerlo.

- Diálogo: las soluciones dialogadas a los conflictos son las verdaderamente constructivas, siempre que los diálogos reúnan una serie de requisitos señalados por la ética discursiva. El que se toma el diálogo en serio: a) Ingresa en él convencido de que el interlocutor puede aportar algo, por eso está dispuesto a escucharlo. b) Está dispuesto a modificar su posición si le convencen los argumentos del interlocutor. c) Está preocupado por buscar una solución correcta y, por tanto, por entenderse con el interlocutor. d) La decisión final ha de atender intereses universalizables, es decir, los de todos los afectados.

- Justicia: históricamente ha recibido muchas formulaciones, siendo la más clásica la de Ulpiano (citado por Boni et al., 2003) al decir que la justicia consiste en "dar a cada uno lo suyo". Las tradiciones liberal y social que confluyen en la Declaración Universal de los Derechos Humanos, acabarán reconociendo que la justicia consiste en dar a cada uno las condiciones para vivir en libertad y en igualdad. En realidad la justicia es un valor que articula los restantes: el respeto a la libertad y su potenciación, el fomento de la igualdad, la realización de la solidaridad, el respeto a las diversas formas de vida, la toma de decisiones comunes a través del diálogo, de manera responsable. Cuando se da todo eso, entonces se da la justicia.

Finalmente, es necesario dar una definición de percepción, puesto que es el elemento que se ausculta con las encuestas a estudiantes y egresados del programa de Ingeniería Agronómica de la Universidad de Caldas. Anne Whyte, asume el concepto de percepción como la toma de conciencia y la comprensión del medio por el individuo en un sentido amplio (Gerritsen, Montero \& Figueroa, 2003). Uno de los aspectos que ha sido privilegiado en los estudios tanto psicológicos como filosóficos sobre la percepción, es el de la elaboración de juicios, que se plantea como una de las características básicas de la percepción (Vargas, 1994). "En la percepción es fundamental el papel recreativo del sujeto y del colectivo que no sólo captan, sino también entienden, deciden y actúan de una determinada forma sobre su entorno inmediato" (Gerritsen et al., 2003, p. 256). El acto de percibir no es homogéneo múltiples factores personales, sociales, políticos, económicos, morales, determinan la realidad percibida subjetivamente (Gerritsen et al., 2003). La percepción puede cambiar con vivencias y procesos formativos como los que se practican en la escuela de Agronomía.

\section{METODOLOGÍA}


Este trabajo es de tipo descriptivo, hermenéutico y exploratorio y se desarrolló en tres escenarios que permitieron cumplir con los objetivos propuestos:

Escala de valores de los agricultores con respecto a su sistema de producción y los componentes ambiental y humano.

Mediante una metodología descriptiva, se trabajó con tres comunidades campesinas:

- La primera comunidad eran jóvenes del primer nivel de la Escuela Granja Agroecológica SoS, ubicada en la vereda La Joya en el municipio de Armero-Guayabal en el departamento del Tolima, provenientes de distintas zonas del país, con una población de 15 personas.

- La segunda en la vereda El Cobre, en el municipio de Fresno, departamento del Tolima, con 22 familias dedicadas principalmente a la producción de café y aguacate.

- La tercera en el municipio de Restrepo, en el departamento del Valle del Cauca, con la Asociación Municipal de Usuarios Campesinos (AMUC).

La herramienta que se utilizó consistió en entrevistas semiestructuradas con preguntas concernientes a: la relación de los campesinos con la tierra, sus cultivos, los recursos naturales, su familia y los otros miembros de la comunidad, participación en decisiones sobre programas de desarrollo rural, creencias alrededor de sus prácticas.

Forma como conciben los estudiantes de Agronomía y los ingenieros agrónomos la escala de valores de los agricultores.

Se realizó una encuesta formal a partir de la información detectada en las tres comunidades referidas, donde cada estudiante dio su percepción con respecto a la escala de valores de los agricultores. Esta encuesta se realizó en tres niveles de formación del estudiante: primer semestre con los juicios con que arriban al programa universitario, en la mitad de la carrera (quinto o sexto semestre) y con la formación completa entregada por la Facultad (noveno o décimo semestre) e ingenieros agrónomos egresados y en sus primeros estadios de actividad laboral. Se aplicó para todos los casos la siguiente fórmula:

\begin{tabular}{|l||c||}
\hline $\begin{array}{l}\text { Tamaño de la población } \\
\text { finito }\end{array}$ & $n=Z_{\alpha}^{2} \frac{N \cdot p \cdot q}{i^{2}(N-1)+Z_{\alpha}^{2} \cdot p \cdot q}$ \\
\hline
\end{tabular}

n: Tamaño muestral, N: Tamaño de la población, Z: Valor correspondiente a la distribución de Gauss 1,96 , para $\alpha=0,05, p$ : Prevalencia esperada del parámetro a evaluar. Se aplica la opción más desfavorable $(p=0,5)$, que hace mayor el tamaño muestral. q: 1 - $p($ Si $p=50 \%, q=50 \%)$, i: Error que se prevé cometer.

- Población primer y segundo semestre: 106. Número encuestas: 49 con error muestral de $10 \%$.

- Población cuarto, quinto y sexto semestre: 128. Número encuestas: 32 con error muestral de $15 \%$.

- Población de últimos semestres (estudiantes practicantes y en procesos de profundización): 83.

Número de encuestas: 30 con error muestral de 14\%.

- Entre 600 estudiantes, se realizaron 111 encuestas, error muestral de $8 \%$.

- Sondeo de opinión por correo entre la población de egresados (600 para los últimos 10 años). Número encuestas: 28 con error muestral de $18 \%$.

Gradación de los valores de los estudiantes, agrónomos y agricultores; puntos en común y diferencias.

A partir de las entrevistas y encuestas realizadas a los agricultores, estudiantes y agrónomos se identificaron los puntos de encuentro y desencuentro, y se sugirieron propuestas formativas en ética agronómica. 


\section{RESULTADOS}

\section{Resultados entrevistas a agricultores}

Los pequeños agricultores consideran que su finca es importante porque es el lugar donde tradicionalmente ha vivido su familia, y que de ahí se deriva una forma de vida que les caracteriza y en la cual se sienten cómodos.

Los pequeños agricultores quisieran disponer de ingresos adicionales por actividades externas a las labores propias de la finca, pero la mayoría considera que lo que ellos desean es conservar la libertad e independencia que tienen en las decisiones y uso del tiempo que poseen trabajando en su finca.

Aunque el trabajo es duro y no da muchos ingresos económicos, reconocen que es una buena manera de invertir el tiempo y de trabajar independientes. Muestran su trabajo con gran sentido de pertenencia, lo ven como una forma de vida y una actividad laboral, sienten orgullo por lo que hacen y lo presentan como una forma de cultura.

A pesar de las dificultades los pequeños agricultores se sienten orgullosos de ser campesinos, ya que valoran la importancia de su rol dentro de la sociedad y se aprecian como personas buenas dentro de esta.

Los pequeños agricultores tienen muchas limitaciones técnicas modernas de conocimientos científicos y de recursos, pero juzgan que dentro de sus posibilidades realizan su trabajo de una manera adecuada. Los cultivos que siembran en su finca tienen un interés económico para la mayoría, pero también siembran para contribuir a la seguridad alimentaria de su familia tanto en cantidad como en calidad; ven la calidad como productos libres de agrotóxicos.

Tienen en su mayoría una postura negativa frente a los agrotóxicos, pero aun así en muchos casos los utilizan. Esto se debe a los deseos de aumentar sus ingresos económicos, pero en zonas donde se les muestran otras alternativas su uso es menor ya que reconocen que ocasionan daños a su salud y al medio ambiente.

Los pequeños agricultores encuentran que es importante lo que los agrónomos les enseñan, ya que son conscientes de la necesidad de ampliar sus conocimientos en aspectos de la agricultura que desconocen.

Todos reconocen la importancia de proteger la naturaleza, ya que son conscientes de lo mucho que dependen de esta para poder seguir existiendo como campesinos. Ante el dilema protección naturaleza e ingreso económico, en algunas comunidades se resuelve a favor de la protección ambiental y en otras lo impone el interés económico.

Contrario a lo que muchos creen, los campesinos se sienten seguros en el campo, ya que califican a las ciudades como más inseguras. Los agricultores mantienen unas buenas relaciones con sus vecinos, y consideran necesaria la cooperación para el desarrollo de sus veredas.

Ellos contemplan más ventajas que desventajas en que sus hijos crezcan en el campo por aspectos concernientes a la salud, aprenden a trabajar y tienen mejores hábitos de vida; solo consideran como desventaja el hecho de que se les dificulta el acceso a la educación.

Los valores de expresión colectiva identificados en los pequeños agricultores entrevistados de las tres comunidades son: responsabilidad, familia, tradición (identidad), trabajo, honorabilidad, cooperación, solidaridad, la educación como valor deseado.

Surgieron valores de expresión individual muy mencionados de orgullo, pertenencia, bienestar, autosuficiencia.

Afloraron otras ventajas de la vida en el campo como: autonomía, libertad, tranquilidad, confianza, seguridad, respeto, diálogo, capacidad de discernimiento; y unas consecuencias de la vida allí donde destacan: felicidad, adaptación, honradez, dignidad, amor. 


\section{Resultados de encuestas a estudiantes}

A manera de definición de valor, los estudiantes de los niveles primeros e intermedios y los egresados. consideran que es la interpretación de la cualidad de un sujeto. En los semestres superiores, el mayor porcentaje entiende que valor es un atributo de un sujeto. Independientemente de la esperada madurez de los egresados, no encuentran en los valores, un orden cultural ideal social que trasciende los sujetos. (Figura 1).

Figura 1. Definición de valor para estudiantes de Agronomía y egresados.

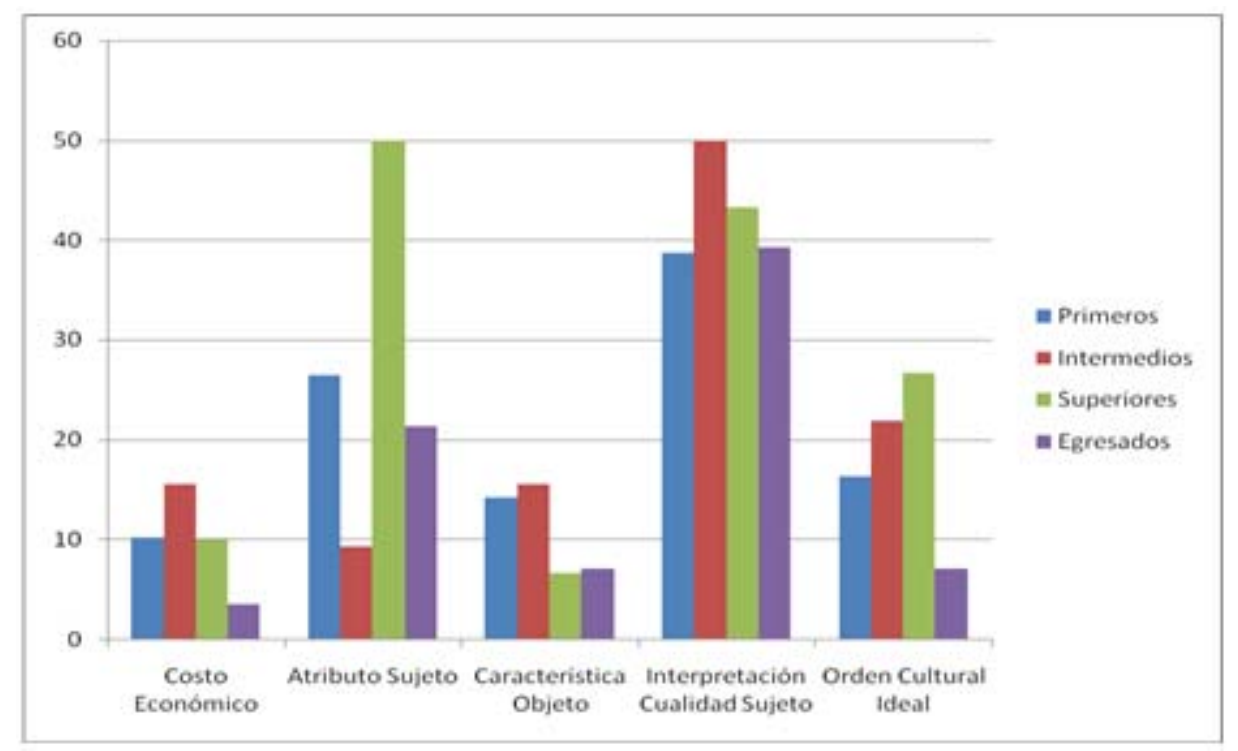

En las siguientes dos Figuras, se presentan las percepciones de los estudiantes respecto de los valores de los pequeños agricultores. Se debe aclarar que en la encuesta se colocan los valores definidos por agricultores y se adicionan tres (justicia, equidad y religiosidad) a manera de control y que no fueron enunciados por los pequeños productores .

Figura 2. Valores de expresión social de los pequeños agricultores percibidos por los estudiantes y egresados de Agronomía.

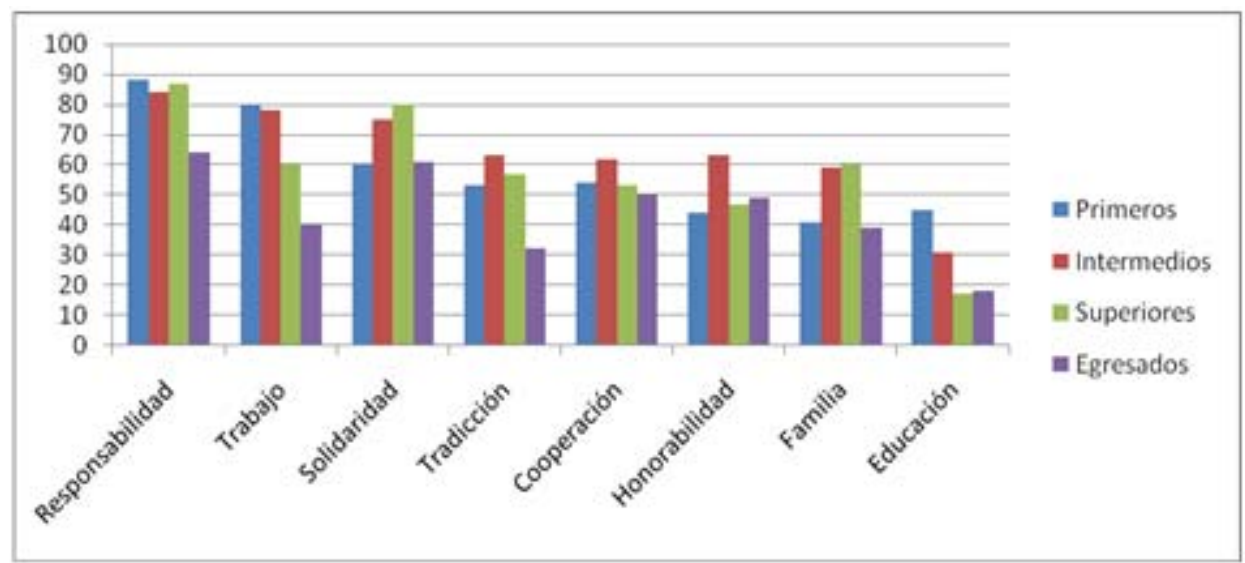

Figura 3. Valores de expresión personal de los pequeños agricultores percibidos por los estudiantes y egresados de Agronomía. 


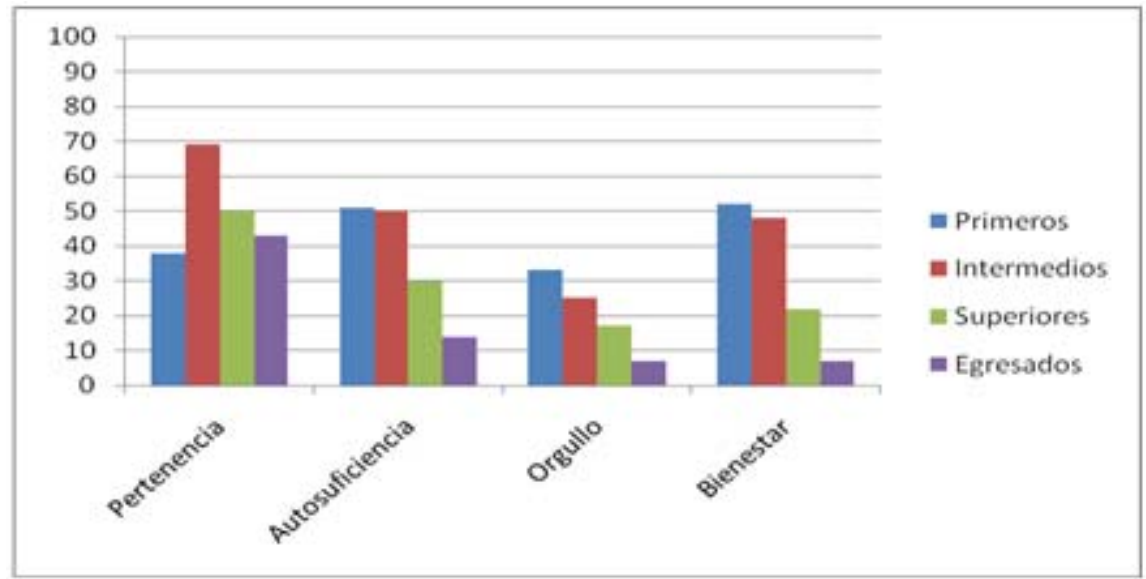

En los primeros semestres los estudiantes consideran como valores de los pequeños agricultores: responsabilidad $(88 \%)$, trabajo $(80 \%)$, solidaridad $(55 \%)$, cooperación $(50 \%)$, bienestar $(50 \%)$ coincidiendo con los agricultores. Los demás valores propuestos por los pequeños agricultores presentan un reconocimiento menor.

En los semestres intermedios de nuevo los estudiantes consideran valores de los pequeños agricultores: la responsabilidad $(84 \%)$, trabajo $(78 \%)$, solidaridad $(75 \%)$, cooperación $(60 \%)$, tradición $(60 \%)$, pertenencia $(69 \%)$. Subvaloran el orgullo de ser campesino (reconocido solo por $25 \%$ de los encuestados).

Para los niveles superiores la responsabilidad (87\%) en los pequeños agricultores es considerada nuevamente como valor que los identifica junto con la solidaridad (80\%), trabajo $(60 \%)$, familia $(60 \%)$, tradición $(57 \%)$, cooperación $(53 \%)$, pertenencia $(50 \%)$, equidad $(43 \%)$ y honorabilidad $(47 \%)$. La diversidad (13\%) y orgullo $(17 \%)$ son considerados por muy pocos como valores de los pequeños agricultores.

En el nivel de egresados, ningún valor se considera identifica determinantemente a los pequeños agricultores, aunque cabe anotar que siguen siendo la responsabilidad (64\%) y solidaridad (61\%) los valores reconocidos por el mayor número de egresados al igual que en los estudiantes de semestres superiores. Al contrario de los pequeños productores, para muy pocos egresados el bienestar $(7 \%)$, el orgullo de ser campesinos $(7 \%)$, la diversidad $(11 \%)$ y la autosuficiencia $(14 \%)$ son valores que identifiquen a los pequeños agricultores. (Figuras 2 y 3 ).

Figura 4. Opinión de estudiantes sobre el origen de los valores de los agricultores.

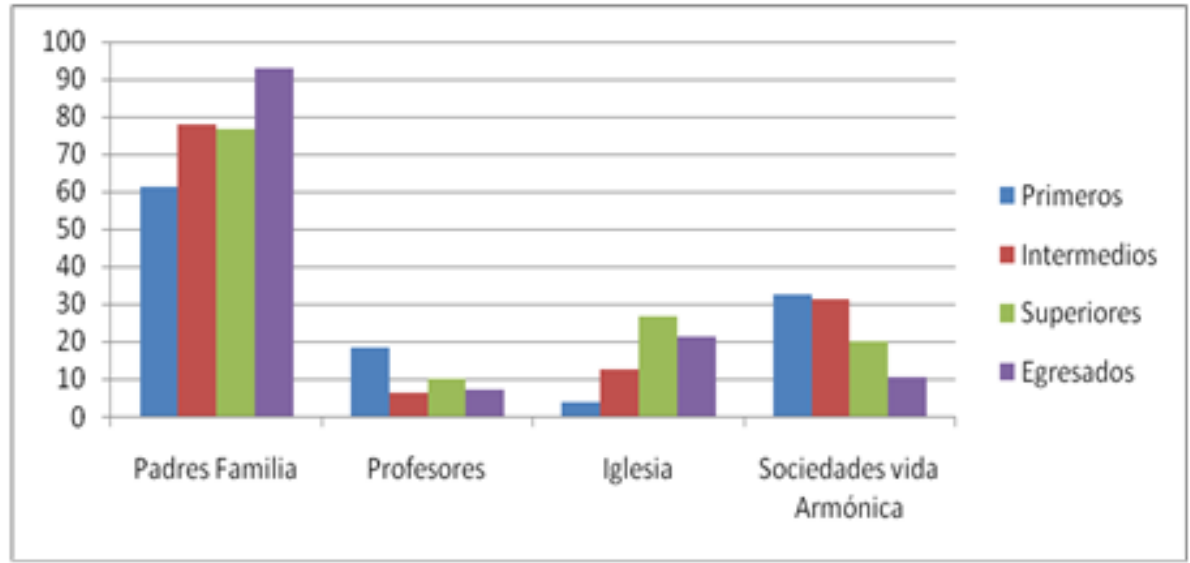

Los niveles intermedios, superiores y los egresados en alto porcentaje afirman que los valores de los pequeños agricultores se estructuran a partir de las enseñanzas de los padres de familia. En $30 \%$ de los estudiantes de los primeros niveles y los intermedios también sugieren la estructuración de los valores a partir de la sociedad para una vida armónica. (Figura 4). 
Figura 5. Opinión estudiantil sobre la tierra como valor para los campesinos.

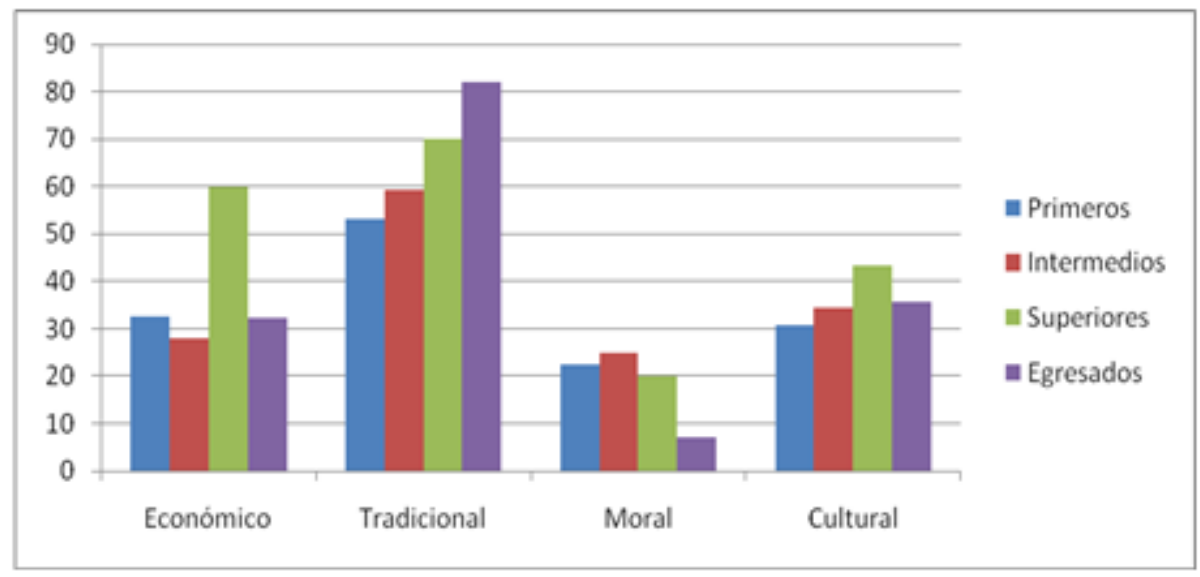

En todos los niveles estudiantiles y egresados perciben que la tierra para los campesinos tiene un valor tradicional, siendo más significativo el porcentaje en el nivel de egresados (82\%). En los niveles superiores además del valor tradicional $(70 \%)$ se considera que la tierra tiene también un valor económico (60\%), y entre 35 y $40 \%$ de los estudiantes de niveles superiores y egresados le ven un valor cultural. (Figura 5 ).

Figura 6. Percepción de estudiantes de Agronomía sobre cómo se sienten los agricultores.

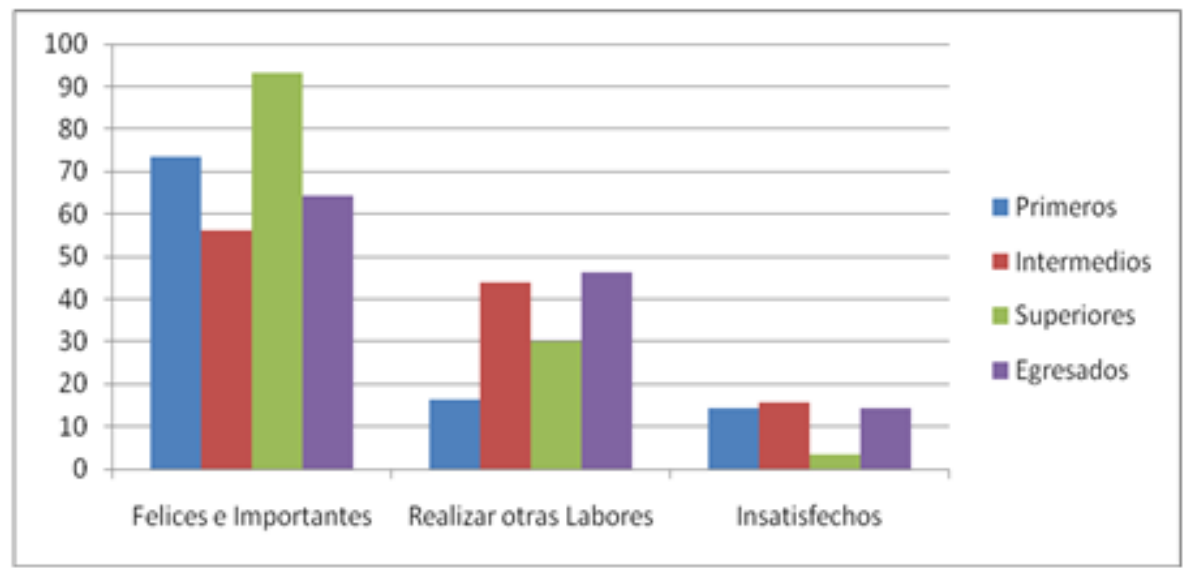

El $93 \%$ de los estudiantes de nivel superior y $72 \%$ de los estudiantes de los primeros niveles, consideran que los campesinos se sienten felices e importantes al realizar las labores del campo; en el nivel intermedio y egresados más de $50 \%$ comparten esta opinión, pero al mismo tiempo $50 \%$ de los estudiantes de estos niveles asumen que los pequeños agricultores quisieran realizar otras labores pero permaneciendo en el campo. (Figura 6).

Figura 7. Mirada de los estudiantes y egresados de Agronomía sobre la postura de los agricultores frente a herramientas tecnológicas (insumos, pesticidas y nuevas tecnologías de producción). 


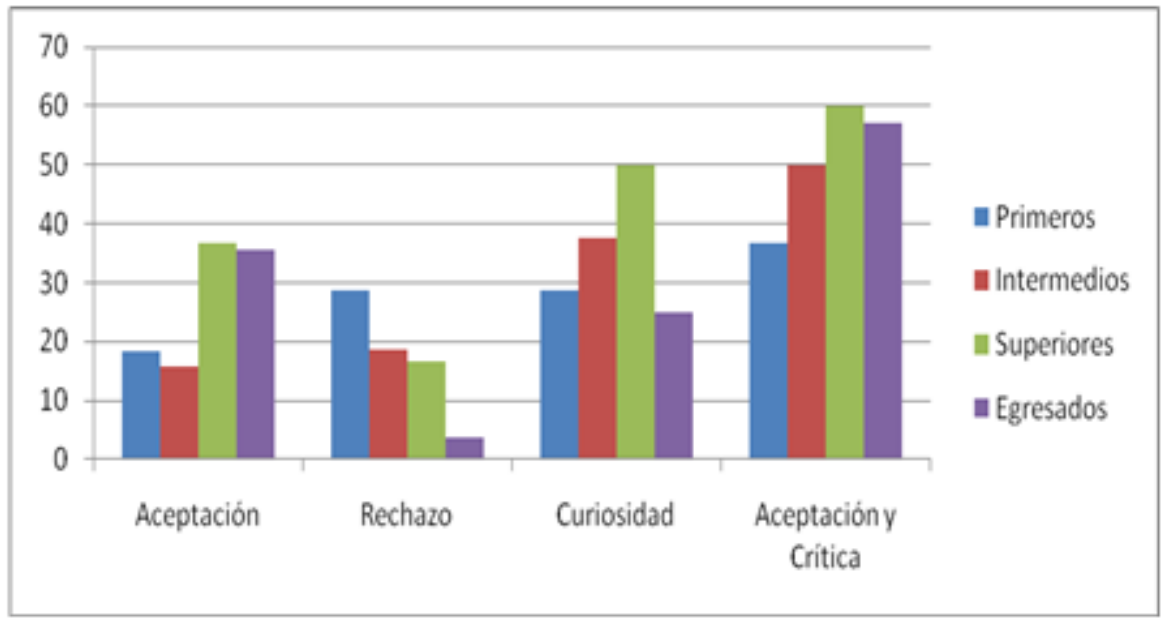

En todos los niveles el mayor porcentaje de las personas encuestadas cree que los pequeños agricultores aceptan estas tecnologías, pero al mismo tiempo critican su impacto económico y ambiental. El porcentaje que considera que los agricultores rechazan estas tecnologías disminuye a medida que aumenta el nivel de estudio. (Figura 7).

Porcentajes mayoritarios de encuestados en todos los niveles opinan que es necesario indagar para la implementación de una nueva tecnología, y $100 \%$ entienden que es importante que los pequeños agricultores sean los encargados de autogestionar su propio desarrollo. (Figuras 8 y 9 ).

Figura 8. Opinión estudiantil sobre indagación a los campesinos en aspectos que se quieran innovar.

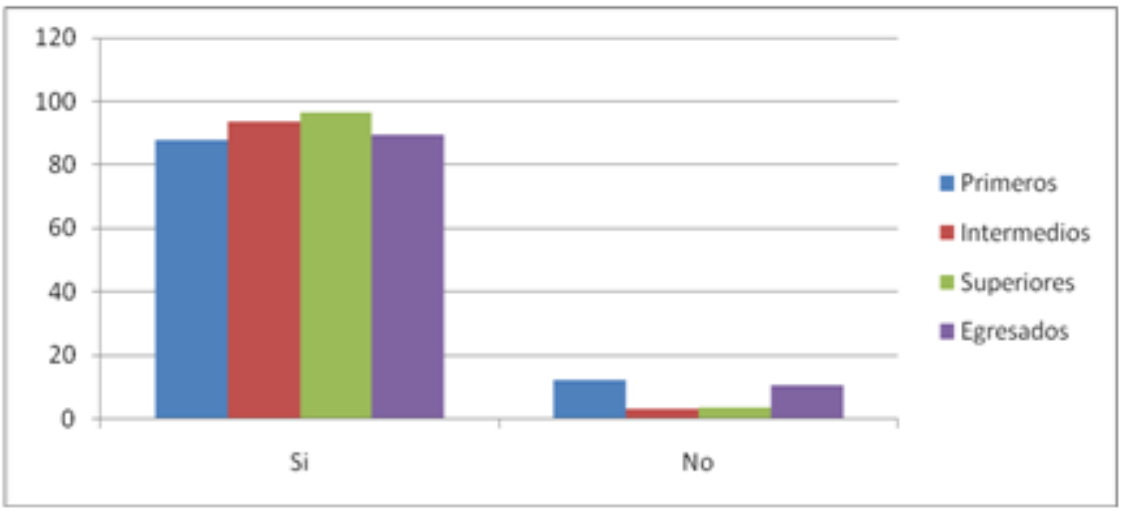

Figura 9. Opinión de estudiantes y egresados sobre la autogestión en los pequeños agricultores.

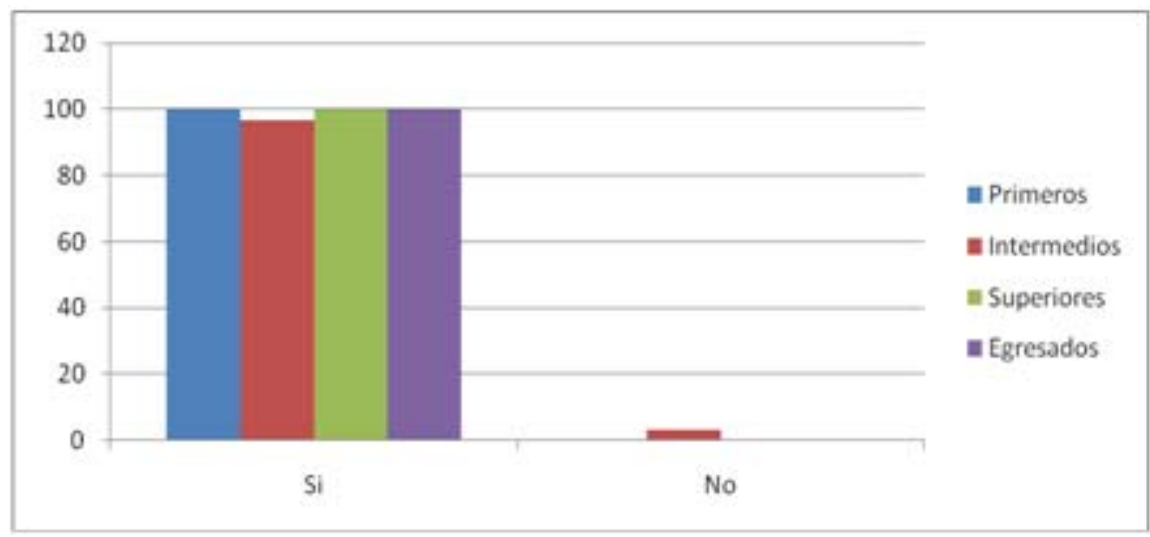


En los primeros niveles, 57\% consideran que los pequeños agricultores se sienten inseguros, y un alto porcentaje (72\%) del nivel intermedio asume que los pequeños agricultores se sienten inseguros, mientras que $73 \%$ de los niveles superiores consideran que los pequeños agricultores se sienten seguros. Por último, en el nivel de egresados $57 \%$ consideran que los pequeños agricultores se sienten seguros y $39 \%$ consideran que se sienten inseguros. Solo los niveles superiores y egresados coinciden con los pequeños productores entrevistados. (Figura 10).

Figura 10. Opinión de estudiantes sobre cómo se sienten los pequeños agricultores viviendo en el campo.

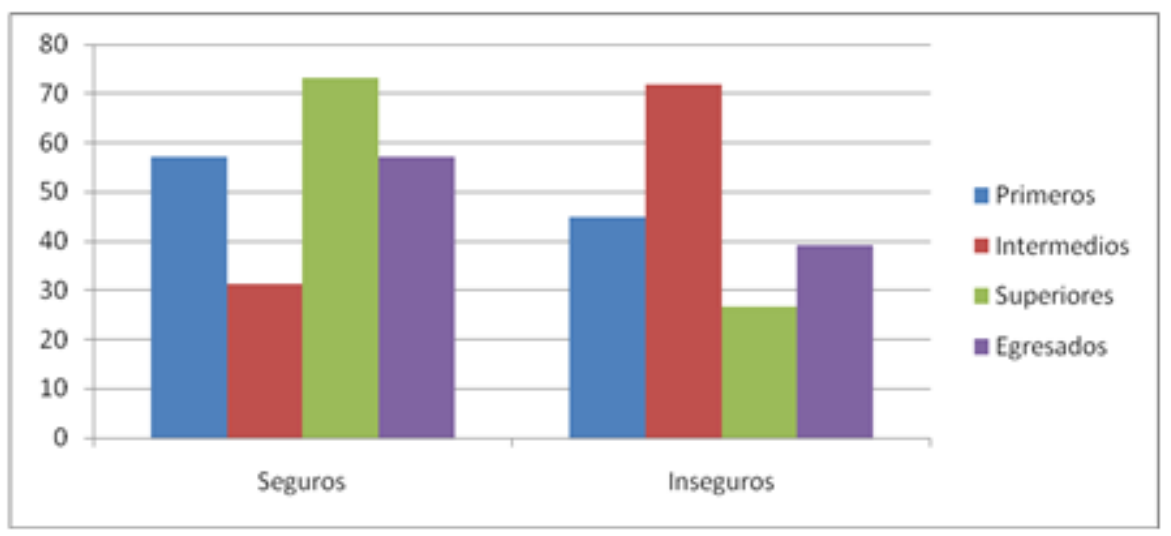

Figura 11. Percepción de los estudiantes y egresados sobre motivaciones de los pequeños agricultores para definir los cultivos que establecerán.

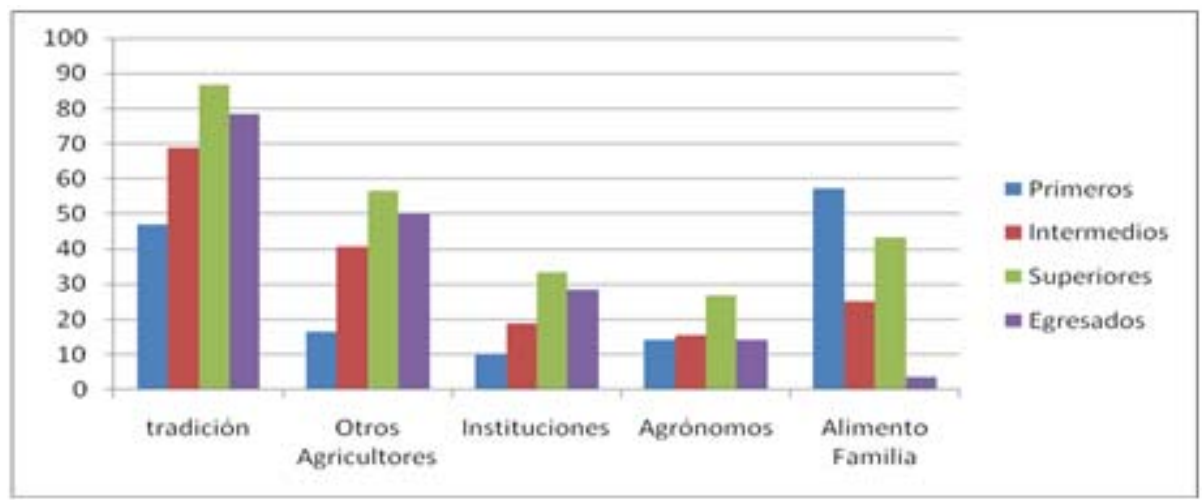

La mayoría de los estudiantes del nivel intermedio, superior y egresados considera que el agricultor toma las decisiones de qué cultivos sembrar de acuerdo con la tradición. En los primeros niveles alrededor de $50 \%$ ven la decisión motivada por la producción de alimento sano y suficiente para la familia, al mismo tiempo que por la tradición. (Figura 11).

Figura 12. Caracterización de las relaciones entre agricultores por parte de los estudiantes. 


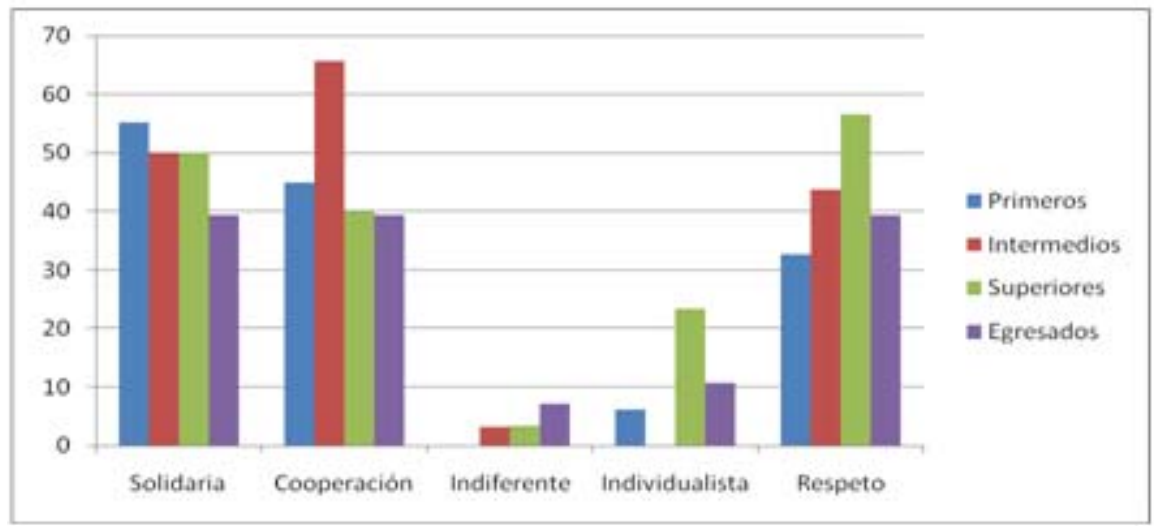

En los distintos niveles consideran que las relaciones entre los pequeños agricultores están determinadas por los valores de solidaridad, cooperación y respeto. Solo en el nivel superior hay una postura considerable de que los pequeños agricultores son individualistas. (Figura 12).

Figura 13. Creencias de estudiantes y egresados sobre la percepción de los pequeños agricultores alrededor del trabajo de los agrónomos.

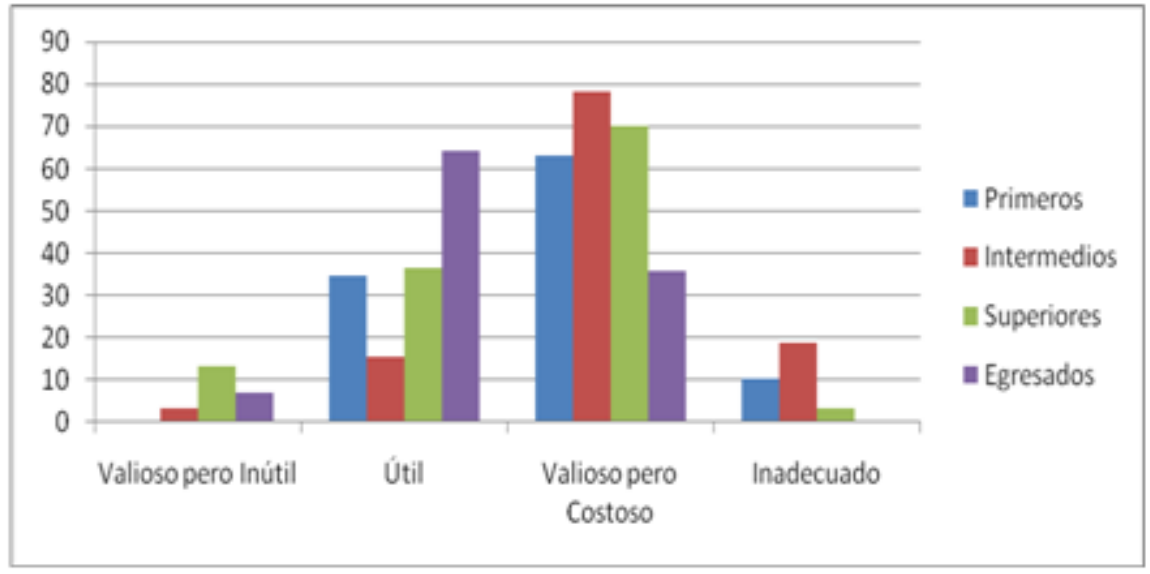

La percepción de los niveles primeros, intermedios y superiores alrededor de la evaluación por parte de los pequeños agricultores sobre el trabajo de los agrónomos, es valioso pero costoso. Para los egresados los pequeños agricultores consideran que el trabajo del agrónomo es útil. (Figura 13).

Figura 14. Concepción de los estudiantes sobre la forma como trabajarían respecto de la inducción de tecnologías con campesinos.

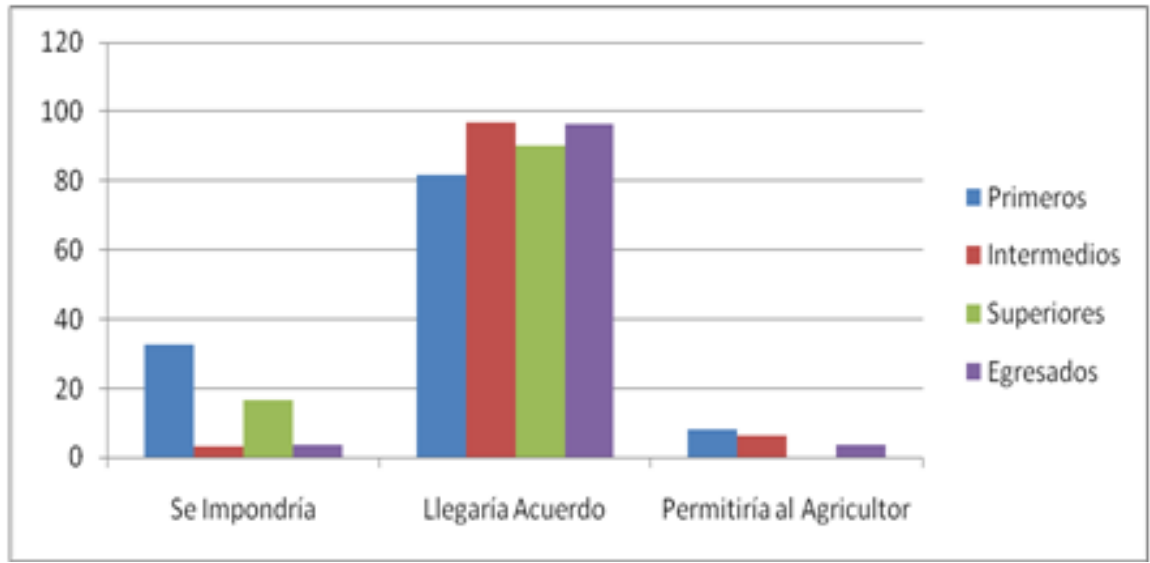


En todos los niveles consideran que al momento de asesorar a un campesino llegarían a un acuerdo. En los primeros niveles $33 \%$ de las personas consideran que impondría su punto de vista. (Figura 14).

En cuanto a la permanencia de los jóvenes en el campo, coinciden con los productores en la afirmación de que es ventajosa. (Figura 15).

Figura 15. Creencias sobre la permanencia de las nuevas generaciones de agricultores en el campo.

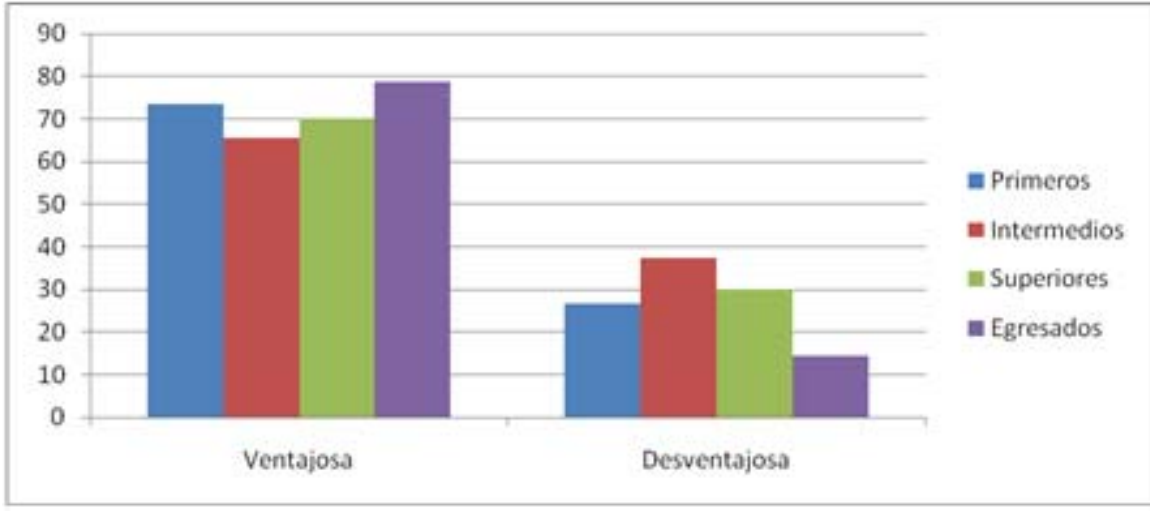

Para un caso hipotético propuesto para identificar el nivel de los discentes en la escala de Kohlberg $64 \%$ de los estudiantes de los primeros semestres se situaron en el nivel postconvencional, seguido por $22 \%$ que se situaron en el nivel convencional y por último $10 \%$ en el preconvencional. En los semestres intermedios se obtuvo como resultado $97 \%$ ubicadas en el nivel postconvencional. En los semestres superiores un alto porcentaje $(83 \%)$ de las personas se ubican en el nivel postconvencional, $13 \%$ en el convencional. En cuanto a los egresados, $90 \%$ se situaron en el nivel postconvencional pero se destaca $10 \%$ restante que se situaron en el nivel preconvencional, a pesar de haber superado todo el proceso de profesionalización universitaria y de experiencia laboral. (Figura 16)

No obstante se podría prever, si esta hipótesis es cierta, que hay un nivel de sensibilidad de los estudiantes frente a los campesinos, lo que se manifestaría en una actitud favorable alrededor de conciliar los discursos técnicos en beneficio de los pequeños agricultores.

Figura 16. Estadio de desarrollo moral de los estudiantes y egresados (escala de Kohlberg).

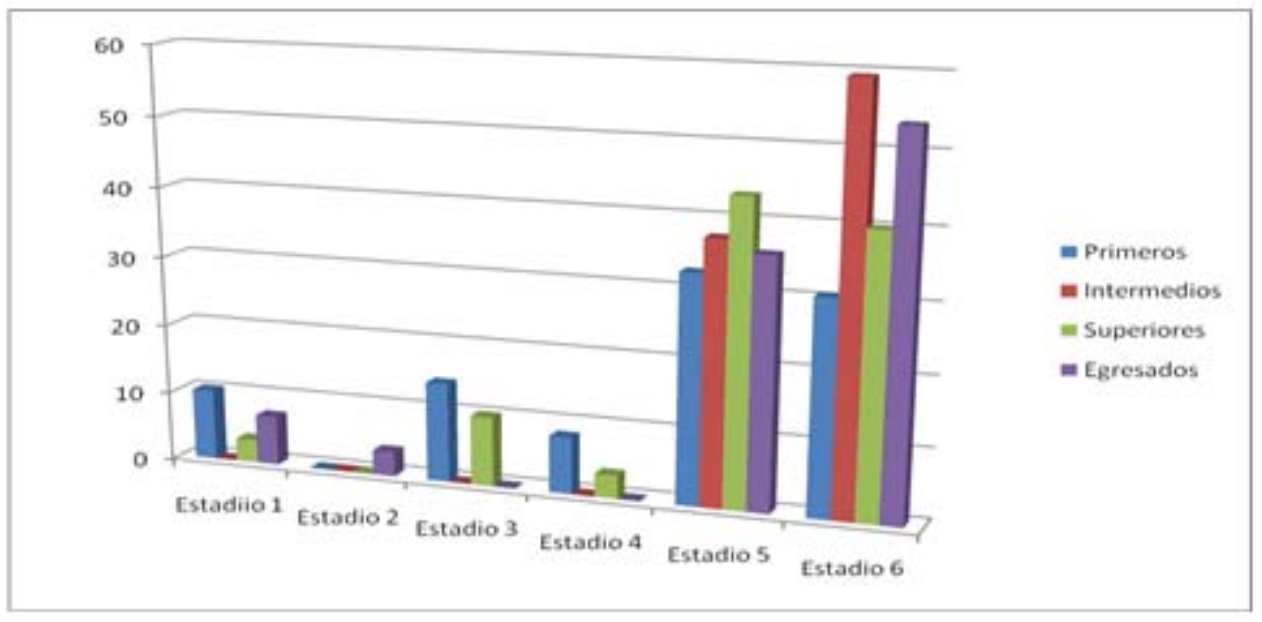

\section{DISCUSIÓN}


De acuerdo con lo observado, los estudiantes de Agronomía y los egresados relacionan los valores con la interpretación de las cualidades de los sujetos, pocos tienen en cuenta que los valores surgen de la interacción entre los miembros de una sociedad, en la que se busca un orden ideal. Esta respuesta de los encuestados se relaciona con la forma como estiman, se estructuran los valores en los pequeños agricultores, ya que solo tienen en cuenta la transmisión directa por parte de los padres, y olvidan nuevamente la importancia que tiene la interacción con los otros miembros de la sociedad, incluidos los agentes de cambio rural en la estructuración de los valores de un sujeto.

Coinciden los estudiantes de Agronomía con los pequeños agricultores en valores centrales como la responsabilidad, trabajo y solidaridad, pero minimizan valores personales muy ponderados por los productores rurales como orgullo, pertenencia y bienestar. En el momento en que el agente de cambio interactúa con ellos, debe tener presente estos valores de los pequeños agricultores, y cuando realiza el ejercicio de acercamiento comunitario debe escuchar el discurso de ellos y ampliar su perspectiva sobre el sujeto con el que se comunica como elemento central que motiva las decisiones de los campesinos. Aunque la mayoría de los encuestados considera que llegarían a un acuerdo negociado, para que la decisión realmente se tome en un punto intermedio entre los intereses del agente de cambio rural y los supuestos beneficiarios, ambos deben reconocer el discurso como inteligible y veraz y situarse en una posición de construcción de bien común.

El artesanado, junto con el campesinado, es una clase de trabajadores anterior a la entrada del capital. El término [campesino], se refiere a una peculiar manera de utilizar los instrumentos de trabajo para producir un objeto generalmente para el consumo, y a la vez es una manera de relacionarse con otros hombres, que involucra formas de producción, distribución e intercambio (Cardini, 2006).

Es importante resaltar aquí además, que su relación con el ambiente difiere sustancialmente de la de los grandes productores. El concepto práctico de conservación [campesina] se refleja en métodos de cultivar, cosechar, desde un ángulo de valores extramercados (Mires citado por Martínez, 2006). Su objetivo es la sustentabilidad racional de su uso y no provocar deterioro ambiental, resolviendo sus necesidades básicas de supervivencia (Martínez, 2006).

Además de aspectos particulares en los procesos de producción, alrededor del objeto, forma, uso, relación con sus pares productivos y consumidores, la manera de habitar el sitio de producción llámese: finca, explotación, es sustancialmente diferente a los grandes y aun de los medianos productores, pues los primeros viven en la finca o parcela, los otros la explotan. La forma de ocupar es guiada por valores diferentes entre estos actores rurales.

Se solía pensar que la constitución moral de la sociedad provenía de causas exógenas a ella. Cuando la legitimidad manaba de la tradición, ella misma hundía sus raíces en lo sobrenatural. Hoy en día la constitución moral de la sociedad es entendida por muchos como endógena, es decir, como producida por ella y de ella dependiente. Los hombres y mujeres [se juntan] comparten y crean, a partir de motivaciones e intenciones, los valores morales que guiarán su cotidianidad. La moral es producto de lo relacional. La moral social [de un grupo determinado de agricultores] convoca intereses, pasiones y estrategias de personas que ocupan posiciones en éstas y otras entidades sociales (Giner, 2002).

El campesino "crece" moralmente a partir de instituciones como la familia, la iglesia y la escuela (todas en su conjunto y como un todo que se resume en un solo individuo, el campesino), en etapas posteriores toma importancia la comunidad local, en que las redes de relaciones interpersonales son esenciales no solo para las estrategias económicas, sino también para otros ámbitos cruciales de la vida humana, como la amistad, la religión, el esparcimiento y el sentido de pertenencia (Durston, 2002). Esto implica que en la lista para determinar lo "conveniente" o "inconveniente" para los pequeños agricultores, por parte de diferentes instituciones presentes en el sector rural, lo valorativo no encuentra un escenario adecuado para ser un elemento preeminente en las decisiones, y no se hace una producción corporativa moral sino una imposición por parte del grupo de poder (entidades gremiales, casas comerciales, asistentes técnicos).

Lo anterior, se puede resumir en palabras de Habermas (citado por Sevilla et al., 2001): "la consciencia tecnocrática refleja no sólo la separación de una situación ética sino que mantiene al hombre aparte de la represión que la ética, como una categoría de la vida, puede ejercer sobre él" (p. 3). Así, cuando la mayoría de los estudiantes de primeros, últimos semestres y egresados dicen hacer un acercamiento de acuerdo sobre tecnologías con el pequeño agricultor se entiende como un intento loable pero no suficiente, pues lo que se impone es "una nueva fórmula de legitimación que proporciona una interpretación del mundo para el hombre moderno [donde se hace] la extensión de los principios científicos a cualquier ámbito de explicación" (Sevilla et al., 2001, p. 3). 
A su vez, la tradición acompaña las decisiones de permanencia, el qué producir, el cómo, que muestra un continuum en donde los saberes circulan entre distintos integrantes de la familia y de la propia comunidad. Aspecto que tiene su correlato en la necesidad de "mostrar", transmitir a otros lo que se sabe, aprender haciendo parece ser la forma más común y cercana a ellos, aunque se muestra interés y respeto por lo impartido y enseñado por agentes externos. Los saberes y la forma de compartirlos entretejen una pedagogía particular enriquecida no sólo por el hacer práctico, sino enriquecidos por formas culturales y valores identitarios propios de un grupo. En el acercamiento hecho a estudiantes de diferentes niveles de formación, la tradición sobresale de los otros valores, se podría decir que la tradición se idealiza por parte de estudiantes y egresados para el universo del agricultor, pero no se logra concretar esta a partir de la seguridad que sienten aquellos al permanecer en el campo y en casos ya muy poco relacionales, por parte de los encuestados con la posibilidad de "ser" de los agricultores.

Los pequeños agricultores recrean su oficio, aunando elementos como la tradición familiar, saberes cargados no solo de valores pragmáticos, sino de posturas valorativas sobre el ambiente, el producto, bienestar de los que producen y consumen; la memoria como herramienta en esas transmisiones; en conjunción con una vocación "especial" mediante una "mirada", "sensibilidad" y percepción peculiar; la experimentación y la prueba; y la consagración como instancia de validación, en la explotación, configuran la construcción de un "capital" que comprende aspectos económicos y conduce también al sentido profundo que posee esta actividad productiva a nivel simbólico y social (Cardini, 2006).

La transformación económica más sustantiva que produce el proceso de modernización, es que ignora que el precio de la tierra va más allá de un cálculo obsesivo de medir el valor de las cosas a través del mercado. La medición se compone de las dimensiones físicas, así como de los derechos de propiedad relativos a los bienes y servicios, o al desempeño de los agentes. Las dimensiones físicas tienen rasgos objetivos (tamaño, peso, color, etc.) y las dimensiones de los derechos de propiedad están definidas en términos legales (North, 1994). Así se fragmenta la postura del campesino "que forja un producto donde intervienen la creatividad, lo afectivo, lo único e irrepetible. Se rompen así las cosmovisiones que explican para cada [grupo] la relación hombre-naturaleza" (Sevilla et al., 2001, p. 6) y hombre-hombre.

En el presente trabajo se muestra una posición generalizada sobre el reconocimiento de la autogestión de los campesinos. Es importante que se dé la razón a la libertad de determinar los caminos que se desean seguir para alcanzar el bienestar por ellos determinado. Sin embargo, son los mismos gestores externos, en muchos casos, los que impiden una recreación de una libertad plena al imponer programas, formas de producción o al abandonar a las comunidades campesinas y no brindar apoyo en diferentes áreas, generando "restricciones a la libertad para participar en la vida social, política y económica” (Sen, 2001, p. 20) de la sociedad colombiana.

El pequeño agricultor posee un pensamiento crítico a pesar de que no siempre tiene acceso a información completa, detallada y veraz. Aun así, a partir de su conocimiento empírico puede observar las desventajas que tiene la aplicación de algunas herramientas tecnológicas impulsadas por los agentes de cambio rural. En las encuestas el mayor porcentaje de personas considera que los pequeños agricultores aceptan pero critican las herramientas basadas en insumos y pesticidas, lo ideal es que los agrónomos en su ejercicio profesional suministren la información completa sobre estas tecnologías para que el pequeño agricultor pueda hacer el ejercicio crítico y tomar libremente la decisión sobre su uso. Esto debe ir acompañado de la indagación sobre la implementación de nuevas técnicas, en lo cual están de acuerdo los recién egresados y futuros agentes de cambio rural de la Universidad de Caldas, (lo muestran los resultados de las encuestas para la pregunta sobre la indagación alrededor de los pequeños agricultores antes de implementar una nueva tecnología). Solo de esta manera pueden los pequeños agricultores autogestionar su propio desarrollo, punto en que también están de acuerdo las personas encuestadas.

Si se establece un discurso entre iguales en el que las relaciones entre los pequeños agricultores, basadas en la solidaridad, cooperación y respeto, se extienda a los agentes externos intervinientes en el cambio rural, se puede lograr que el trabajo del agrónomo sea reconocido como útil. Se esperaría que el agrónomo reconociese al agricultor como un fin y no como un medio, donde no solo las instituciones y casas comerciales imponen su criterio con los técnicos como instrumentos útiles y agricultores como mercado consumidor.

Finalmente, en un primer acercamiento que requerirá estudios más detallados y precisos sobre el desarrollo moral de los estudiantes y egresados, donde se ubican de manera hipotética mayoritaria en un nivel ideal de madurez moral (postconvencional), se tomará lo afirmado por Barra (1987):

la influencia importante para el desarrollo moral no reside en algún grupo o institución social (familia, grupo de pares, instituciones secundarias), sino en la oportunidad que cualquier grupo o institución brinde para la asunción de roles, para que el individuo se sienta responsable y partícipe en su 
ámbito social. En este sentido, aunque la secuencia de los estadios morales es universal, la cultura influye en el ritmo de desarrollo, pudiendo acelerar o retardar el paso de un estadio a otro. (p. 16)

La mirada que se hace por parte de los estudiantes y egresados sobre la comunidad campesina está mediada por instrumentos técnicos, económicos, políticos y minoritariamente sociológicos. La reflexión desde la ética está ausente, se desnuda a los campesinos de esta postura que es connatural con cualquier ser humano. El acercamiento de los estudiantes con las pequeñas comunidades agrarias es esporádico durante su proceso de formación profesional, de hacerlo lo ético no está en el escenario de "crecimiento relacional" de los futuros profesionales, y no es que no sean éticos, es que el argumento ético no se posiciona como un ente regulador sino que se supone está presente en muchos casos intuitivamente.

\section{BIBLIOGRAFÍA}

- Aguilera, Shamara. (2004). Desarrollo, población y uso de los recursos en el Valle de Uxpanapa. Tesis de Licenciatura, Universidad Veracruzana. Obtenido en octubre de 2010, desde http://www.ciesasgolfo.edu.mx/istmo/docs/tesis/UXPANAPA\%20S.\%20AGUILERA/CAPITULO\%20I.pdf

- Alarcón, Rodolfo, y Bernal, Manuel. (2003). Hacia una reflexión ética en la universidad. Tunja, Colombia: Uniboyacá. 291p.

- Alútiza, Juan Carlos. (2005). Las fuentes normativas de la moralidad pública moderna. Contribuciones de Durkheim Habermas y Rawls. Tesis Doctoral, Universidad Pública de Navarra. Obtenido en noviembre de 2010, desde http://www.unavarra.es/puresoc/pdfs/tesis/alustiz/02BCapitulo_Cuarto.pdf

- Barra, Enrique. (1987). El desarrollo moral: una introducción a la Teoría de Kohlberg. Revista Latinoamericana de Psicología, 19(1), 7-18. Obtenido en noviembre de 2010, desde http://redalyc.uaemex.mx/pdf/805/80519101.pdf

- Bebbington, Anthony. (1990). Los conocimientos técnicos de los campesinos: su papel en la elaboración de una teoría sobre el desarrollo tecnológico de la agricultura andina. Documents d'anàlisis geogràfica,17, 7-26. Obtenido en octubre de 2010, http://www.raco.cat/index.php/DocumentsAnalisi/article/viewFile/41507/52334

- Blanch, J. M. (2007). Psicología Social del Trabajo. En Aguilar, M. y Reid, A., (Coords.), Tratado de Psicología Social. Perspectivas Socioculturales. (pp. 210-238). MéxicoBarcelona: Anthropos/UAM. Obtenido en noviembre de 2010, desde http://www.ascofapsi.org.co/documentos/2010/ v_catedra/sesion_1/ps_social_trabajo.pdf

- Boni, A., Lozano, J. F., y Monterde, R. (2003). Valores en la dirección y gestión de proyectos de cooperación al desarrollo de las organizaciones no gubernamentales. Departamento de Proyectos de Ingeniería, Universidad Politécnica de Valencia. Obtenido en octubre de 2010, desde http://www.sld.cu/galerias/pdf/sitios/infodir/valores_en_proyectos_cooperacion.pdf

- Cardini, Laura. (2006). Reflexiones sobre el "valor" de la producción artesanal en la ciudad de Rosario, Argentina. Maguaré, 20, 125-143.

- Ceretti, Graciela, y García, Zulma. (2006). Sujetos y racionalidad en una zona desertificada. Revista de Temas Sociales,10(18). Obtenido en octubre de 2010, desde http://www.revistakairos.org

- Cortina, Adela. (2000). Ética mínima: Introducción a la filosofía práctica. 6 ed. Madrid: Tecnos. Obtenido en octubre de 2010, desde http://www.scribd.com/doc/30725484/CortinaAdela-Etica-Minima

- Dote Cofré, Ignacio. (2006). Psicología del aprendizaje y del desarrollo, aporte de las neurociencias. Obtenido en octubre de 2010, desde http:/lwww.dote.cl/arte/ensayos/Desarrollo\%20Moral.pdf

- Durston, John. (2002). El capital social campesino en la gestión del desarrollo rural. CEPAL. p. 8. Obtenido en octubre de 2010, desde www.eclac.cl/publicaciones/xml/0/11700/Indice.pdf

- Esquivel, Héctor. (2009). Reflexión sobre el valor de la educación y educación en valores. La lámpara de Diógenes, revista de filosofía, 18 y 19, 169-190. Obtenido en noviembre de 2010, desde http://www.Idiogenes.buap.mx/revistas/18/169.pdf

- Gerritsen, Peter, Montero, María, y Figueroa, Pedro. (2003). El mundo en un espejo. Percepciones campesinas de los cambios climáticos en el occidente de México. Economía, Sociedad y Territorio, IV(014), 253-278. Toluca, México. Obtenido en mayo de 2010, desde http://redalyc.uaemex.mx/pdf/111/11101403.pdf

- Giner, Salvador. (2002). La Urdimbre moral de la modernidad. Anales de la Cátedra Francisco Suárez, 36, 63-100. Obtenido en noviembre de 2010, desde http://www.ugr.es/ filode/pdf/contenido36_4.pdf 
- Guindon, André. (1990). Evolución y desarrollo moral. Madrid: Promoción Popular Cristiana.

- Habermas, Jürgen. (1999). Teoría de la acción comunicativa: Racionalidad de la acción y racionalización social. Tomo 1. Madrid: Grupo Santillana de Ediciones.

- Lara, Pía. (1990). La identidad social en Habermas: Entre el consenso y la alteridad. Cuadernos de Filosofía del Derecho, 7, 257-272. Obtenido en octubre de 2010, desde http://www.cervantesvirtual.com/servlet/SirveObras/ 01371630233495944102257/cuaderno7/doxa7_08.pdf

- Lazega, Emmanuel. (2004). Racionalidad, disciplina social y estructura. REDES: Revista Hispana para el análisis de redes sociales, 5(6). Obtenido en noviembre de 2010, desde http://revista-redes.rediris.es

- Leyton, Fabiola. (2005). La Ética de la Responsabilidad y la Ética Extensionista. Tesis de Grado Maestría, Universidad de Chile. Obtenido en noviembre de 2010, desde http://www.fabiola.cl/2005/tesis_etica/Etica_Responsabilidad_y_Extensionista.pdf

- Martínez Castillo, Róger. (2006). Acercamiento a una agroecología indígena. Obtenido en octubre de 2010, desde http://www.reflexiones.fcs.ucr.ac.cr/documentos/82_1/acercamiento.pdf

- (2008). Agricultura tradicional campesina: características ecológicas. Tecnología en Marcha, 21(3), 3-13. Obtenido en noviembre de 2010, desde http://www.tec.ac.cr/sitios/Vicerrectoria/vie/editorial_tecnological Revista_Tecnologia_Marcha/pdf/tecnologia_marcha_21-3/3,13.pdf

- Maza Pereda, Antonio. (n.f.). Tradición: un valor que "hace" a la familia. Obtenido en noviembre de 2010, desde http://www.churchforum.org/tradicion-un-valor-que-hacefamilia.htm

- North, Douglas. (1994). ¿Qué queremos decir cuando hablamos de racionalidad? Estudios Públicos, 53, 7. La traducción de este ensayo fue hecha por el Centro de Estudios Públicos con la debida autorización de Kluwer Academic Publishers, de la versión original en inglés "What do we mean by rationality?", publicada en 1993 en Public Choice, 77(1).

- Papacchini, Angelo. (2000). El porvenir de la ética: la autonomía moral, un valor imprescindible para nuestro tiempo. Revista de estudios sociales, 5, 32-49. Obtenido en noviembre de 2010, desde http://redalyc.uaemex.mx/pdf/815/81500505.pdf

- Pérez, José Luis. (2002). La noción rawlsiana de autorrespeto. Revista de Ciencias Sociales, 47, 99-122. Obtenido en noviembre de 2010, desde http://www.dirittoequestionipubbliche.org/page/2004_n4/studi_J_PerezTrivino.pdf

- Portillo, Carlos. (2005). La Teoría de Lawrence Kohlberg. Obtenido en mayo de 2009, desde http://ficus.pntic.mec.es/ cprf0002/nos_hace/desarrol3.html

- Quintero, Marieta. (2004). Aspectos cognitivos del constructivismo del aprendizaje moral: psicología moral y ética discursiva. Pedagogía y Saberes, 20, 79-86.

- Rodríguez, S., Herrera, L., Quiles, O., y Álvarez, J. (2008). El valor familia en estudiantes universitarios de España: análisis y clasificación. Enseñanza e Investigación en Psicología, 13(2), 215-230. Obtenido en noviembre de 2010, desde http://redalyc.uaemex.mx/pdf/292/29213202.pdf

- Salazar, Diana, Serna, Ciro, y López, Francisco. (2007). Relación ética y medio ambiente en un mundo globalizado. Manizales: Editorial Universidad de Manizales.

- SEN, A. (2001). Desarrollo y Libertad. Traducción de Esther Rabasco y Luis Toharia. 3 ed. Bogotá: Editorial Planeta S.A. 356p.

- Sevilla Guzmán, Eduardo, González de Molina, Manuel, y Mielgo, Antonio Alonso. (2001). El desarrollo rural de la otra modernidad: Elementos para recampesinizar la agricultura industrializada desde la agroecología. Congreso Vasco de Sociología, Bilbao, 1-3 de marzo de 2001. Obtenido en septiembre de 2010, desde http://www.cifaed.es/downloader.php? path=archivos/publicaciones/\&nomrecurso=58.pdf

- Sieglin, Verónica. (2004). Modernización rural y devastación de la cultura campesina. México: Editorial Plaza y Valdés y UANL. 396p. Obtenido en septiembre de 2009, desde http://books.google.com.co.

- Siurana A, Juan Carlos. (2000). Lla idea de sujeto en la ética del discurso de karl-otto apel aplicada al problema de las directrices anticipadas en el ámbito de la ética biomédica, Tesis doctoral Universidad de Valencia Servicio de Publicacions C/ Artes Gráficas, 13 bajo 46010 València España. Versión Pdf en roderic.uv.es/bitstream/handle/10550/15476/siurana.pdf?sequence=1 Creado 13122004 Revisado Septiembre 2010

- Universidad Nacional de Colombia. (2010). Compromiso ético Universidad Nacional de Colombia. Obtenido en noviembre de 2010, desde http://www.simege.unal.edu.co/unimedios/ COMPROMISO_ETICO_UNIVERSIDAD_NACIONAL.pdf

- Vasco, Eloísa. (1989). La formación de valores en la educación. Revista de la Universidad de la Salle, 11(17), 145-154. 
- Valdés, Margarita. (1991). Dos aspectos en el concepto de bienestar. Doxa: Cuadernos de Filosofía del Derecho, 9, 69-89. Obtenido en noviembre de 2010, desde http://www.cervantesvirtual.com/servlet/SirveObras/ 02472776436247507976613/cuaderno9/doxa9_04.pdf

- Vargas, Luz María. (1994). Sobre el concepto de percepción. Alteridades, 4(8), 47-53. Obtenido en noviembre de 2010, desde http://www.uam-antropologia.info/alteridades/alt84-vargas.pdf

- Vila Merino, Eduardo. (2004). Pedagogía de la ética: De la responsabilidad a la alteridad. Athenea Digital, 6, 47-55. Obtenido en octubre de 2010, desde redalyc.uaemex.mx/pdf/537/53700604.pdf

- Villarroel, Raúl. (2004). Ética del discurso. En Pérez, Manuel, Escríbar, Ana y Villarroel, Raúl, (Eds.), Bioética: Fundamentos y dimensión práctica. Santiago de Chile: Editorial Mediterráneo. Obtenido en octubre de 2010, desde www.plataforma.uchile.cl

1.

I.A.

Ingeniero

Agronómo

2. I.A. M.Sc. en Fitopatología. Estudios en Maestría de Epistemología. Profesora Catedrática Universidad de Caldas

3. I.A. Esp Especialista en Adninistración. Estudios en Maestría de Epistemología. Profesor Títular Universidad de Caldas. 